\title{
Autologous hematopoietic stem cell transplantation in systemic sclerosis induces long-lasting changes in B cell homeostasis toward an anti-inflammatory $B$ cell cytokine pattern
}

\author{
Michael Gernert ${ }^{*}$, Hans-Peter Tony, Eva Christina Schwaneck, Ottar Gadeholt and Marc Schmalzing
}

\begin{abstract}
Background: Autologous hematopoietic stem cell transplantation (aHSCT) is performed in patients with aggressive forms of systemic sclerosis (SSc). The profile of B cell reconstitution after aHSCT is not fully understood. The aim of this study was to investigate changes of B cell subsets and cytokine production of B cells in patients with SSC after aHSCT.

Methods: Peripheral blood of six patients with SSC was collected at defined intervals up to 16 months after aHSCT. Immunophenotyping was performed, and B cell function was determined by measuring cytokine secretion in supernatants of stimulated B cell cultures.

Results: Within 1 month after aHSCT, a peak in the percentage of $\mathrm{CD}_{3} 8^{++} / \mathrm{CD} 10^{+} / \mathrm{lgD}$ transitional B cells and $\mathrm{CD} 38^{+}$ ${ }^{+} / \mathrm{CD}_{2} 7^{++} / \mathrm{lgD}{ }^{-}$plasmablasts was detected. Long-term changes persisted up to 14 months after aHSCT and showed an increased percentage of total B cells; the absolute B cell number did not change significantly. Within the B cell compartment, an increased $C D 27 / \mathrm{gD}^{+}$naïve $B$ cell percentage was found whereas decreased percentages of $C D 27^{+} /$ $\mathrm{lg} \mathrm{D}^{+}$pre-switched memory, $\mathrm{CD} 27^{+} / \mathrm{lgD}{ }^{-}$post-switched memory, and $\mathrm{CD}_{2} 7^{-} / \mathrm{lgD}^{-}$double-negative $\mathrm{B}$ cells were seen after aHSCT. Cytokine secretion in B cell cultures showed significantly increased IL-10 concentrations 13 to 16 months after aHSCT.

Conclusion: A changed composition of the B cell compartment is present for up to 14 months after aHSCT indicating positive persisting effects of aHSCT on B cell homeostasis. The cytokine secretion profile of B cells changes in the long term and shows an increased production of the immune regulatory cytokine IL-10 after aHSCT. These findings might promote the clinical improvements after aHSCT in SSc patients.
\end{abstract}

Keywords: Systemic sclerosis, B cells, Memory B cells, naïve B cells, Autologous hematopoietic stem cell transplantation, Interleukin-10

\footnotetext{
* Correspondence: gernert_m1@ukw.de

Department of Medicine II, Rheumatology and Clinical Immunology,

University of Würzburg, Oberdürrbacher Str. 6, 97080 Würzburg, Germany
}

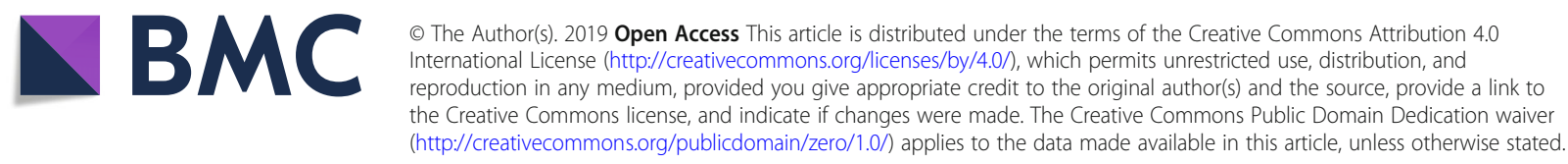




\section{Background}

Systemic sclerosis (SSc) is a heterogeneous and devastating autoimmune disease characterized by inflammation, vasculopathy, and fibrosis. Fibrosis occurs in the skin and the internal organs and is often refractory to standard immunosuppressive therapy [1]. Depending on the extent of skin involvement, SSc can be divided into a limited cutaneous form ( $\mathrm{lcSSc}$ ) or a diffuse cutaneous form $(\mathrm{dcSSc})$ [2]. SSc is the rheumatic disease with the highest case mortality, mainly driven by pulmonary hypertension and lung fibrosis [3]. The use of immunosuppressive therapy is restricted to patients with diffuse progressive skin disease and progressive inner organ involvement mainly of the lungs, whereas vasculopathy can hardly be controlled by immunosuppressive therapy.

So far, studies have not been able to show that conventional and biologic disease-modifying antirheumatic drugs (DMARDs) have more than a limited effect on disease manifestations; however, there is some evidence for the efficacy of mycophenolate mofetil and cyclophosphamide $[4,5]$. Case series suggest a slight benefit of rituximab to skin and lung involvement $[6,7]$. A phase 3-study investigated the efficacy of tocilizumab in SSc patients and indicates positive effects on lung fibrosis [8].

Of all treatment options for SSc autologous hematopoietic stem cell transplantation (aHSCT) seems to be the most efficacious therapy, but treatment toxicity and treatment-related mortality have to be considered in this population with limited organ function. Three randomized trials (one unicenter, two multicenter) have shown superior efficacy concerning skin and lung involvement in patients with diffuse cutaneous SSc compared to treatment with intravenous cyclophosphamide once per month for 6 months [9] or intravenous cyclophosphamide once per month for 12 months [10, 11]. The two multicenter trials also have shown a long-term survival benefit, although early treatment-related mortality was increased $[10,11]$. For aHSCT, patients' stem cells are mobilized using chemotherapy and granulocyte colony-stimulating factor (G-CSF). These stem cells were enriched by $\mathrm{CD} 34^{+}$-selection and were reinfused after an immunoablative conditioning regimen consisting of cyclophosphamide and anti-thymocyte globulin (ATG) in most cases. Nevertheless, relapses and disease progression can occur also after aHSCT, and so far, there are no studies that have examined treatment options after aHSCT and few data is available about how aHSCT evokes its effects.

The pathogenesis of SSc has been widely investigated. Interstitial fibrosis is the major mechanism causing organ damage. This fibrosis seems to be promoted by disturbed $\mathrm{T}$ cell subsets $[12,13]$ and by secretion of pro-fibrotic cytokines from $\mathrm{CD}^{+} \mathrm{T}$ cells [14]. Vasculopathy is correlated with specialized circulating angiogenic
T cells [15]. Furthermore, an altered B cell system has been described demonstrating that B cells play an important role in the pathogenesis of SSc [16]: Autoimmune properties of $\mathrm{B}$ cells are increased in SSc patients by an overexpression of CD19 [17] and B cell activating factor (BAFF) [18]. Plasma cells of SSc patients produce anti-topoisomerase $1 /$ Scl70 auto-antibodies, which are associated with a more extensive skin involvement [19], and alteration of B cell subsets in SSc patients are described [20]. Disturbed cytokine profiles in SSc patients are important in creating a pro-fibrotic state [21].

An important $B$ cell subset in autoimmune diseases is the $\mathrm{CD} 19^{+} / \mathrm{CD}^{2} 7^{-} / \mathrm{IgD}^{-}$(double-negative) B cell subset. Although they do not express CD27, double-negative B cells seem to belong to the memory compartment, as their immunoglobulin receptors show somatic hypermutations [22]. In rheumatoid arthritis (RA) and systemic lupus erythematosus (SLE), double-negative B cells are increased [23, 24]. In concordance with that, higher numbers of double-negative $B$ cells correlate with a better response to rituximab in RA patients [25].

Interleukin (IL)-10 is a cytokine of special interest for the investigation of the pathogenesis of SSc. IL-10 terminates inflammatory processes and stimulates growth and differentiation of various cell types including $B$ cells, $T$ cells, NK cells, dendritic cells, and endothelial cells among others [26]. Downstream the IL-10 receptor, the signal transducer and activator of transcription 3 (STAT3) pathway and the phosphoinositide 3-kinase (PI3K) pathway are activated, resulting in the inhibition of antigen presentation and the inhibition of secretion of pro-inflammatory cytokines mainly in macrophages and dendritic cells [27]. That is why special attention was turned to IL-10-producing B cells (Bregs) which can be located within the $\mathrm{CD} 19^{+} / \mathrm{CD} 24^{\text {high }} / \mathrm{CD} 38^{\text {high }}$ or $\mathrm{CD} 19^{+} /$ $\mathrm{CD} 24^{\text {high }} / \mathrm{CD}^{2} 7^{+}$subpopulation [28]. A reduction of Bregs [29] and a reduced ability to produce IL-10 is described in SSc patients [30].

The aim of the present study was to elucidate the changes in B cell subsets and in the B cell function in $\mathrm{SSc}$ patients after receiving aHSCT. Those insights might indicate treatment targets for SSc patients with progressive or relapsing disease after aHSCT.

\section{Patients and methods \\ Patients}

Six patients (five female, one male; mean age 44.2 years, range from 23 to 58 years) who met the ACR/EULAR criteria [31] for SSc were included in the study. At the time of aHSCT, five patients had a diffuse cutaneous form $(\mathrm{dsSSc})$ and one patient a limited cutaneous form (lcSSc), two patients showed positivity for Scl70-antibodies, and four patients had pulmonary 
fibrosis due to SSc. Patients' characteristics are summarized in Table 1.

We performed a prospective, non-interventional cohort study, which was approved by the local ethics committee. All patients gave their written informed consent. Participation in this study had no influence on their therapy.

\section{Myeloablative autologous hematopoietic stem cell transplantation}

All patients suffered from progressive disease under conventional immunosuppressive treatment and therefore underwent aHSCT in the years 2014 to 2017 . They received a treatment protocol analogous to that used in the ASTIS trial [10]: Patients received $2 \mathrm{~g} / \mathrm{m}^{2}$ cyclophosphamide for mobilization of autologous hematopoietic stem cells together with a minimum daily dose of $105 \mu \mathrm{g}$ granulocyte colony-stimulating factor (G-CSF), starting on day 2 after cyclophosphamide, followed by leukapheresis. The autologous hematopoietic stem cells underwent CD34 ${ }^{+}$-selection using immunomagnetic separation (CliniMACS CD34 Complete Kit, Miltenyi Biotec, Bergisch Gladbach, Germany) in four out of six patients. In two patients, stem cells were not $\mathrm{CD} 34^{+}$-selected due to low stem cell numbers in the leukapheresis product. Then, patients obtained an immunoablative conditioning regimen containing a total of $200 \mathrm{mg} / \mathrm{kg}$ cyclophosphamide (on days 1-4) plus $30 \mathrm{mg} / \mathrm{kg}$ rabbit ATG (on days $2-5$ ). The autologous hematopoietic stem cells (minimum dose of $2.0 \times 10^{6} \mathrm{CD} 34^{+}$cells per kilogram body weight) were then reinfused (on day 6 ).

\section{Immunophenotyping}

Peripheral blood was obtained before (range 5 to 12 weeks) and after (at month 1, 2, 3, 5-7, and 12-14) aHSCT. Distribution of $\mathrm{B}$ cell subsets was obtained from fresh blood via immunophenotyping. Staining was performed with the Navios cytometer (Beckman Coulter, Krefeld, Germany) using the following antibodies: CD19-phycoerythrin-cyanin (PC) 7, CD20-allophycocyanin (APC) 750, CD45-Krome Orange, CD27-phycoerythrin-Texas Red-X (ECD), CD38-PC5.5 (each Beckman Coulter, Krefeld, Germany), IgD-fluorescein isothiocyanate (FITC), CD10-phycoerythrin
(PE) (each BD Biosciences, San Jose, CA), CD21-Pacific Blue (Exbio, Prague, Czech Republic), and IgM-APC (BioLegend, San Diego, CA). Lymphocytes were identified by using forward versus sideward scatter. Within the lymphocyte gate, at least 3000 events were collected and $\mathrm{CD}^{+} 9^{+}$ cells were identified as B cells. Transitional B cells were defined as $\mathrm{CD} 38^{++} / \mathrm{CD} 0^{+} / \mathrm{IgD}^{+}$, pre-switched memory B cells as $\mathrm{CD} 27^{+} / \mathrm{IgD}^{+}$, post-switched memory B cells as $\mathrm{CD} 27^{+} /$ $\mathrm{IgD}^{-}$, double-negative $\mathrm{B}$ cells as $\mathrm{CD}^{2} 7^{-} / \mathrm{IgD}^{-}$, naïve $\mathrm{B}$ cells as $\mathrm{CD}_{27} / \mathrm{IgD}^{+}$, and circulating plasmablasts as $\mathrm{CD} 38^{+}$ ${ }^{+} / \mathrm{CD} 27^{++} / \operatorname{IgD}{ }^{-}$.

\section{Preparation of peripheral blood mononuclear cells (PBMCs) and B cell enrichment}

Peripheral blood in EDTA-tubes $(15-20 \mathrm{ml})$ was obtained before (range 6 to 12 weeks) and after (range 13 to 16 months) aHSCT and processed with Ficoll-Paque Plus separation (GE Healthcare, Munich, Germany) according to the manufacturer's instructions to receive PBMCs. PBMCs were stored in liquid nitrogen before they were incubated with CD19 monoclonal antibody-coupled microbeads to separate B cells by magnetic cell sorting (MACS; Miltenyi Biotec, Bergisch Gladbach, Germany). Each PBMC sample was loaded onto two MACS columns successively to achieve a B cell purity over $95 \%$.

\section{$B$ cells cultures and cytokine measuring}

The enriched B cells were incubated over $24 \mathrm{~h}$ with $10 \mu \mathrm{g} /$ $\mathrm{ml}$ cytosine guanine dinucleotide (CpG ODN 2006, InvivoGen, Toulouse, France) in 96-well plates at a concentration of $0.5-1 \times 10^{6}$ cells $/ \mathrm{ml}$. Supernatants were then collected and stored at $-80^{\circ} \mathrm{C}$. Cytokines from supernatants of the B cell cultures were measured using cytometric bead array (CBA flex set; BD bioscience, San Jose, CA) in a LSR II cytometer (BD bioscience, San Jose, CA). Concentrations of cytokines were calculated using FCAP array software (BD bioscience, San Jose, CA).

\section{Statistical analysis}

Samples were tested for normal distribution by performing Shapiro-Wilk tests and Q-Q plots. If normal distribution was determined, means \pm standard deviations

Table 1 Characteristics of the study population*

\begin{tabular}{|c|c|c|c|c|c|c|c|}
\hline Patient & Sex & Age at aHSCT & Cutaneous form & Scl-70 positivity & Pulmonary fibrosis & Troponin positivity & CD34 ${ }^{+}$-selected graft \\
\hline 1 & F & 38 & dc & + & + & - & + \\
\hline 2 & $\mathrm{~F}$ & 53 & lc & - & - & + & + \\
\hline 3 & M & 58 & dc & - & + & + & - \\
\hline 4 & $\mathrm{~F}$ & 47 & dc & - & + & - & + \\
\hline 5 & $\mathrm{~F}$ & 23 & dc & + & - & + & - \\
\hline 6 & $\mathrm{~F}$ & 46 & dc & - & + & - & + \\
\hline
\end{tabular}

${ }^{*}$ f female, $M$ male, $d c$ diffuse cutaneous form, $I c$ limited cutaneous form 
(SD) were calculated and differences were analyzed using a two-tailed paired $t$ test. If normal distribution could not be determined, medians with interquartile ranges (IQR) were calculated and Wilcoxon signed-rank tests were performed to detect differences between groups. SPSS Statistics v 25.0 (IBM, Armonk, NY) and Excel (Microsoft, Redmond, WA) were used. Differences were considered significant when $P$ values were less than 0.05 .

\section{Results}

\section{Increased percentage of total B cells after aHSCT}

In the first month after aHSCT, the percentage of total B cells within the lymphocyte gate showed the lowest values $(0.6 \pm 0.5 \%$; mean $\pm \mathrm{SD})$ compared to the baseline values before aHSCT $(6.8 \pm 5.3 \% ; P=0.030)$. In that stage of the lymphocyte repopulation, the predominant population were NK cells (data not shown). Total B cell percentages showed the highest values 20.7 weeks (range 10-47 weeks) after aHSCT. Total B cell percentages increased significantly 4.2 -fold from $6.8 \pm 5.3 \%$ at baseline to $28.5 \pm 12.9 \% 3$ months after aHSCT $(P=0.013)$. A significant increase in total B cell percentages was maintained until 14 months after aHSCT (Fig. 1a). The longest follow-up in one patient comprised 2 years and showed a sustained 4.1-fold increase of the total B cell percentage ( $4.8 \%$ at baseline compared to $19.5 \% 2$ years after aHSCT).

Absolute numbers of $\mathrm{B}$ cells had the lowest values 1 month after aHSCT and increased continuously over time, starting from the second month after aHSCT, without showing any significant changes compared to baseline (Fig. 1b). Lymphocyte numbers (Fig. 1c) showed a mean of $1478.3 \pm 929.9 / \mu \mathrm{l}$ at baseline. The minimum of lymphocyte numbers was detected 1 month after aHSCT $(605.0 \pm 277.8 / \mu \mathrm{l} ; P=0.039)$. From month two after aHSCT, lymphocyte numbers recovered and did not show significant differences to baseline.

\section{Early phase of $B$ cell repopulation}

The subset analysis within the B cell compartment revealed a specific repopulation pattern after aHSCT. In the first month after aHSCT, a 10-fold increase could be detected in the percentage of plasmablasts $\left(\mathrm{CD} 38^{+}\right.$ $\left.{ }^{+} / \mathrm{CD} 27^{++} / \mathrm{IgD}^{-}\right)$from $2.8 \pm 4.6 \%$ at baseline compared to $28.7 \pm 22.7 \% 1$ month after aHSCT $(P=0.040$; Fig. 2a). The absolute numbers of plasmablasts did not change significantly after aHSCT (Fig. 2b). A 21-fold increase in the percentage of transitional B cells $\left(\mathrm{CD} 38^{++} / \mathrm{CD} 10^{+} /\right.$ $\operatorname{IgD}^{+}$) from $2.4 \pm 3.2 \%$ at baseline compared to $50.8 \pm$ 29.9\% 1 month after aHSCT $(P=0.008)$ was present (Fig. 2c). Absolute numbers of transitional $B$ cells showed a peak of $25.6 \pm 10.7 / \mu \mathrm{l} 2$ months after aHSCT compared to baseline $1.6 \pm 2.0 / \mu \mathrm{l} \quad(P=0.026$; Fig. $2 \mathrm{~d})$. Those changes diminished over time, with no significant

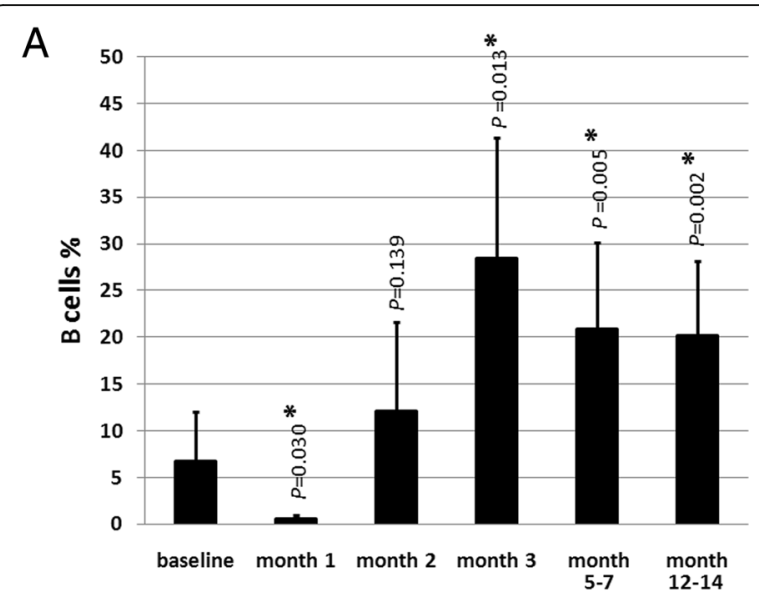

B
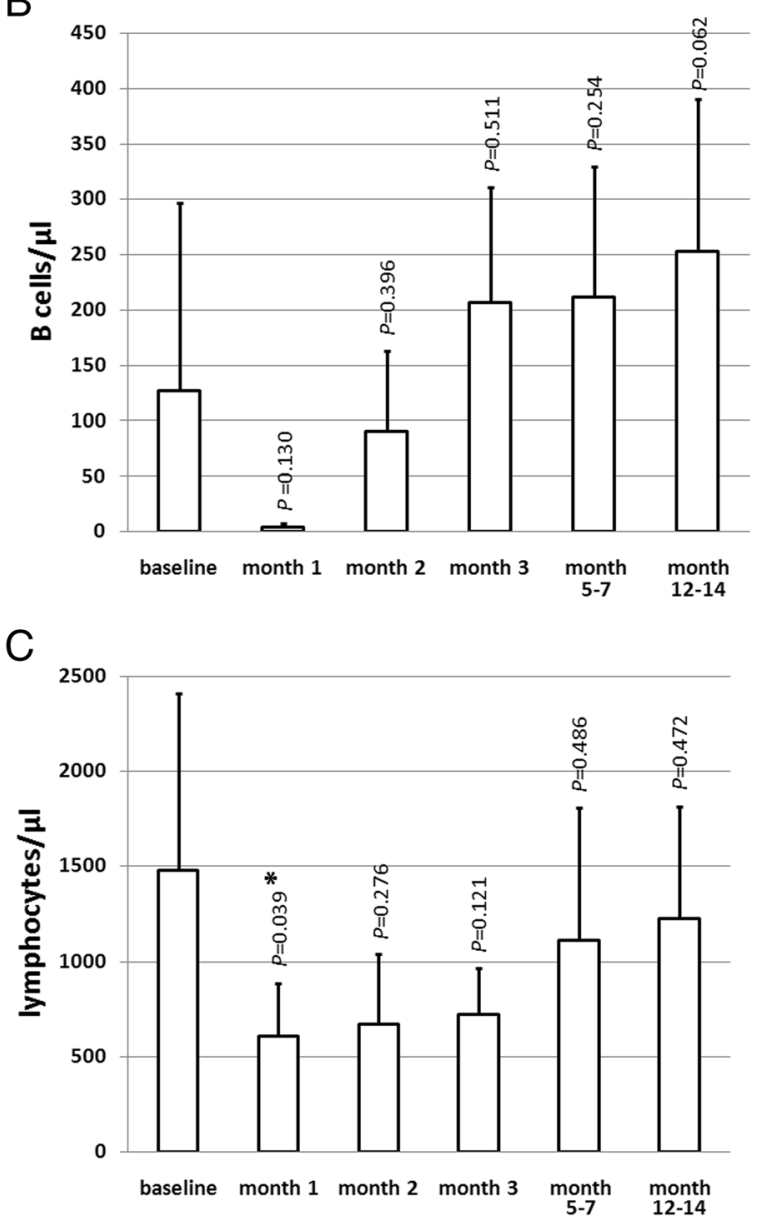

Fig. 1 Changes of B cell percentages (a), B cell numbers (b), and lymphocyte numbers (c) after aHSCT. a B cell percentages within the lymphocyte gate at different time points. Baseline (before aHSCT), month 1, month 2, month 3, months 5-7, and months 12-14 after aHSCT. b Corresponding B cell numbers $/ \mu$ l and $\mathbf{c}$ lymphocyte numbers/ $\mu$ lat respective time points. $n=6$ (except months 2 and 3 $n=5)$; mean $\pm S D$; ${ }^{*}$ significant $(P<0.05)$ difference compared to baseline in the two-tailed paired $t$ test 


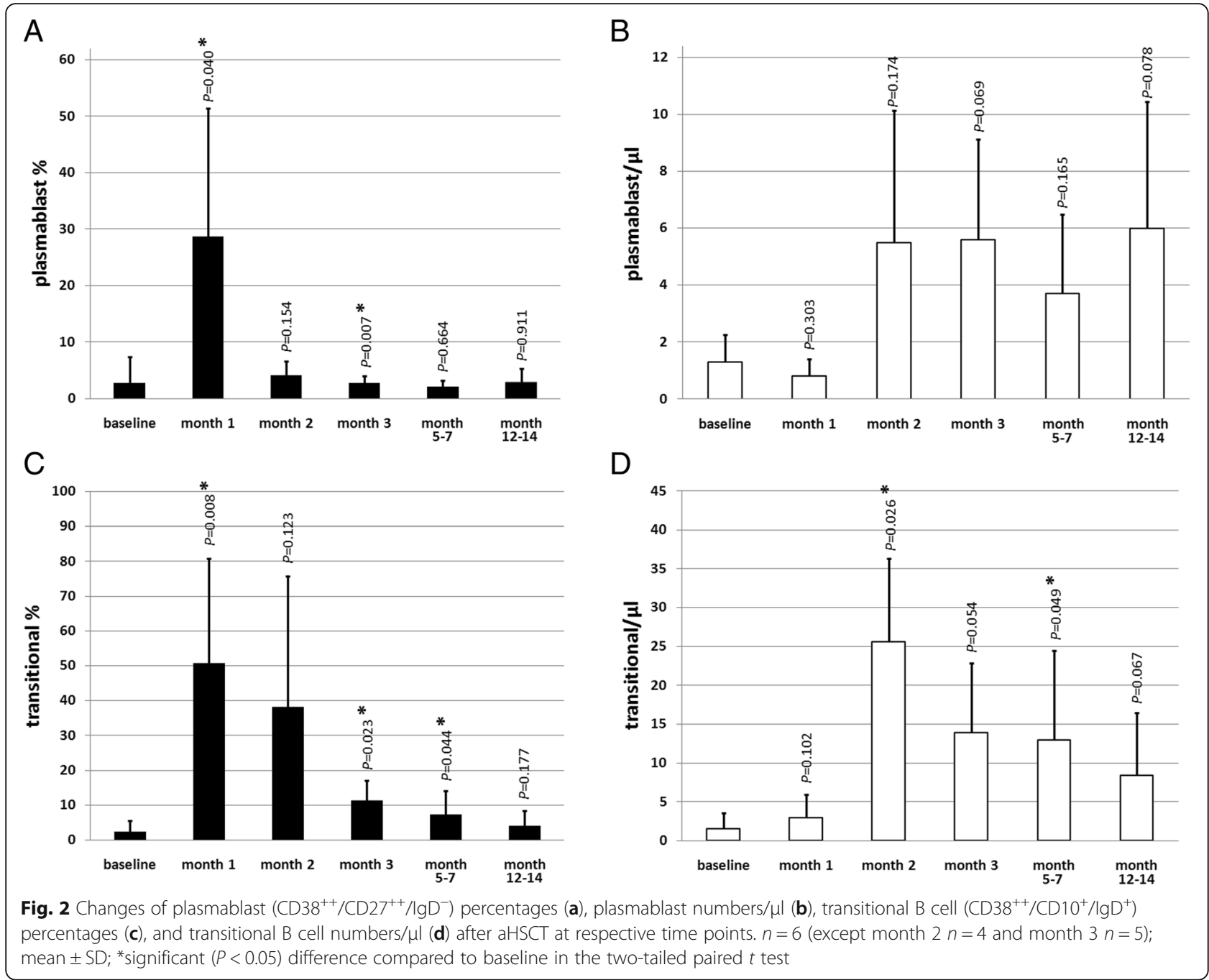

differences in plasmablast and transitional B cell percentages and absolute numbers 1 year after aHSCT compared to baseline.

\section{Long-term changes in B cell subsets after aHSCT}

Starting from 2 months after aHSCT, distinct changes in the B cell subsets could be detected. The B cell repopulation was mainly accomplished by naïve $B$ cells $\left(\mathrm{CD} 27^{-} / \mathrm{IgD}^{+}\right)$. Naïve $\mathrm{B}$ cell percentages increased significantly 1.4 -fold from $65.4 \pm 13.2 \%$ at baseline to 91.9 $\pm 3.9 \% 1$ year after aHSCT $(P=0.004$; Fig. $3 a)$. Also, absolute naïve $B$ cell numbers showed a significant increase from $88.9 \pm 131.4 / \mu \mathrm{l}$ at baseline to $233.6 \pm 127.7$ / $\mu l 1$ year after aHSCT $(P=0.024$; Fig. $3 b)$. The memory B cell compartment $\left(\mathrm{CD} 27^{+}\right)$did not recover until 1 year after aHSCT. The pre-switched memory B cell percentages $\left(\mathrm{CD}_{2} 7^{+} / \mathrm{IgD}{ }^{+}\right)$declined from $9.1 \pm 4.3 \%$ at baseline to $3.1 \pm 1.4 \% 1$ year after aHCT $(P=0.029$; Fig. $3 \mathrm{c})$. Similar changes could be detected in the post-switched memory B cells $\left(\mathrm{CD} 27^{+} / \operatorname{IgD}{ }^{-}\right)$: Percentages declined from $18.9 \pm 11.4 \%$ at baseline to $3.1 \pm 2.4 \% 1$ year after aHSCT $(P=0.023$; Fig. 3e). Absolute numbers of pre-switched (Fig. 3d) or post-switched memory B cells (Fig. $3 \mathrm{f}$ ) did not change significantly after aHSCT. Double-negative $\mathrm{B}$ cell percentages $\left(\mathrm{CD}^{-} 7^{-} / \mathrm{IgD}^{-}\right)$ showed a constant decrease after aHSCT $(6.6 \pm 3.2 \%$ at baseline versus $2.0 \pm 1.0 \% 1$ year after aHSCT; $P=0.015$; Fig. 3g), whereas absolute numbers of double-negative $B$ cells showed no long-term changes (Fig. 3h).

\section{Increased IL-10 secretion by B cells after aHSCT}

To evaluate the influence of aHSCT on the B cell function of SSc patients, B cell cultures were stimulated with CpG ODN and cytokines were measured in the supernatants. The effect of CpG ODN stimulation on the cytokine secretion is described in Additional file 1: Figure S1. B cells after aHSCT showed a higher secretion of IL-10 compared to the levels before transplantation. The median concentration of IL-10 before aHSCT was 0.8 $\mathrm{pg} / \mathrm{ml}$ (IQR $0.0-2.5 \mathrm{pg} / \mathrm{ml}$ ) versus $8.6 \mathrm{pg} / \mathrm{ml}$ (IQR 3.9- 

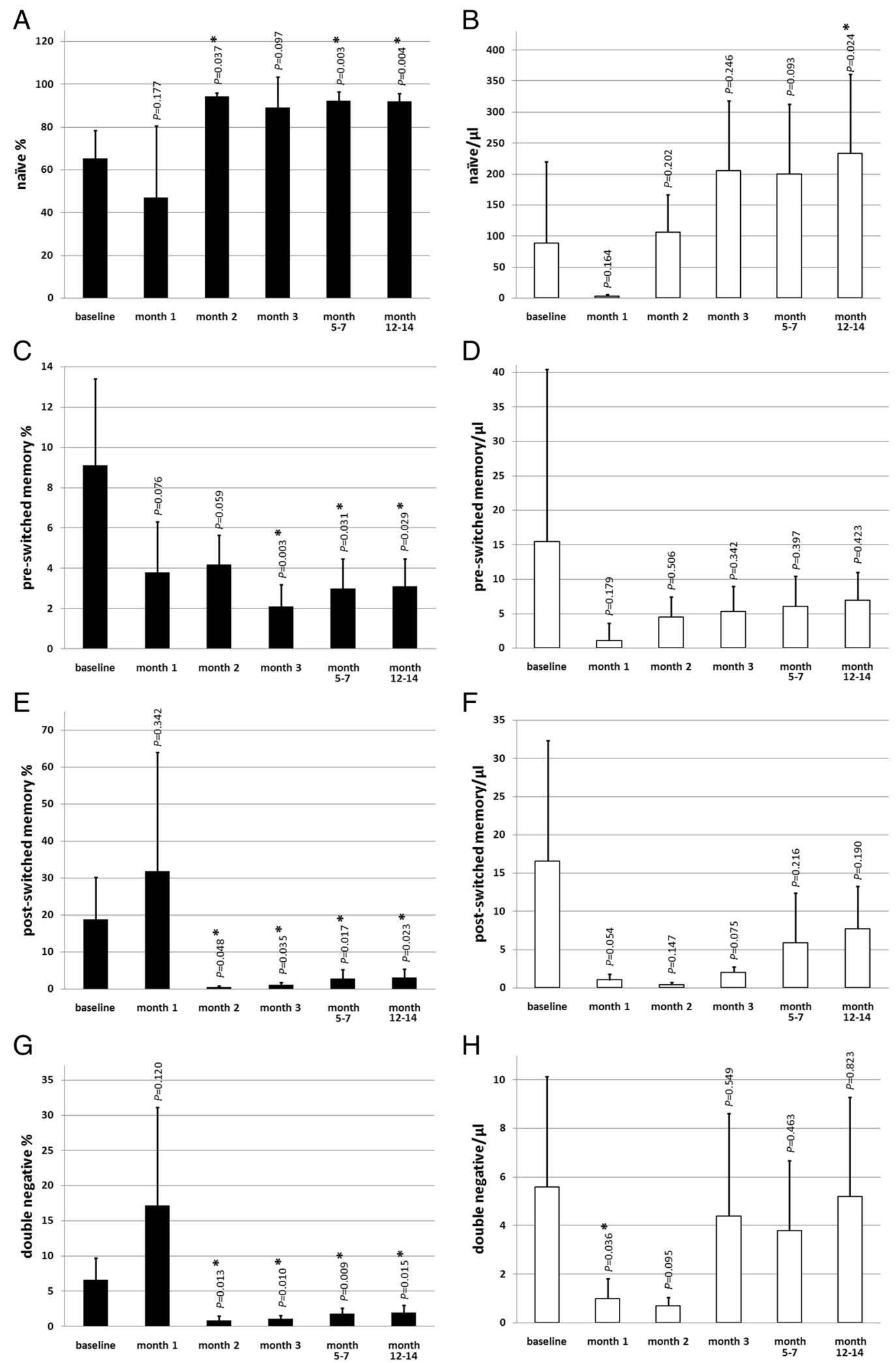

Fig. 3 (See legend on next page.) 
(See figure on previous page.)

Fig. 3 Naïve B cell $\left(C D 27^{-} / \mathrm{lgD}^{+}\right)$percentages $(\mathbf{a})$ and naïve B cell numbers $/ \mu l(\mathbf{b})$, pre-switched memory B cells $\left(C D 27^{+} / \operatorname{lgD}^{+}\right)$percentages $(\mathbf{c})$ and pre-switched memory B cell numbers $/ \mu \mathrm{l}(\mathbf{d})$, post-switched memory B cell $\left(C D 27^{+} / \mathrm{lgD}^{-}\right)$percentages $(\mathbf{e})$ and post-switched memory B cell numbers $/ \mu \mathrm{l}(\mathbf{f})$, double-negative B cell $\left(\mathrm{CD}^{2} 7^{-} / \mathrm{lgD} \mathrm{D}^{-}\right)$percentages $(\mathbf{g})$ and double-negative B cell numbers $/ \mu \mathrm{l}(\mathbf{h})$, at baseline and after aHSCT at respective time points. $n=6$ (except month $2 n=4$ and month $3 n=5$ ); mean $\pm S D$; ${ }^{*}$ significant $(P<0.05)$ difference compared to baseline in the two-tailed paired $t$ test

$11.2 \mathrm{pg} / \mathrm{ml})$ after aHSCT $(P=0.043)$. No significant changes were observed in the secretion of the following cytokines after aHSCT: IL-6, IL1- $\beta$, TNF- $\alpha$, TGF- $\beta$, IL-12/IL-23, and G-CSF (Fig. 4). No secretion of IL-1- $\alpha$ could be detected (data not shown).

\section{Improved skin involvement and stabilized lung function of SSc patients after aHSCT}

Clinical data was assessed before and 10 to 18 months after aHSCT. The mean modified Rodnan skin score (mRSS) of the six SSc patients improved after aHSCT. Before aHSCT, the mean mRSS was $21.8 \pm 11.3$ (mean mRSS \pm SD; range 9-41); after aHSCT, the mean mRSS was $11.5 \pm 7.3$ (range $2-20 ; P=0.005$ ). The mean diffusing capacity for carbon monoxide (DLCO) showed stable values, which means no worsening of lung function. Before aHSCT, DLCO was $45.3 \pm 20.7 \%$ (mean \% of predicted DLCO $\pm \mathrm{SD})$, and after aHSCT, it was $47.5 \pm$ $23.8 \%(P=0.315)$. The mean forced vital capacity (FVC) was stable over the course of the study. Before aHSCT, it was $80.0 \pm 19.1 \%$ (mean \% of predicted FVC $\pm \mathrm{SD}$ ), and after aHSCT, it was $88.3 \pm 24.0 \%(P=0.066)$. Morphological pulmonary fibrosis, documented as interstitial lung disease by thoracic computed tomography, showed stable findings or even a decline in fibrotic manifestations after aHSCT.

\section{Discussion}

This prospective study analyzed the composition of the peripheral B cell compartment and the cytokine profile of purified B cells upon CPG stimulation of SSc patients before and after aHSCT.

After aHSCT, an increased total B cell percentage within the lymphocytes was seen. Within the B cell compartment, increased naïve $B$ cells, decreased memory $B$ cells (pre- and post-switched), and decreased double-negative B cells could be detected. Those changes were long-term changes and stable at least until 1 year after aHSCT.

Similar repopulation patterns after aHSCT have been reported in other autoimmune diseases, for example SLE or multiple sclerosis with an incline in naïve B cell frequencies and a decline in memory B cells [32, 33]. Also, in hematologic malignancies, an increased naïve $B$ cell compartment after aHSCT was described [34].

The B cell repopulation pattern after aHSCT described is similar to the repopulation after B cell depleting treatment with rituximab. Application of rituximab caused a long-lasting reduction of memory B cells [35], persisting even after repeated treatment with rituximab in RA patients [36]. In contrast to the treatment with rituximab after aHSCT, the total B cell percentage is increased 1 year after treatment. An increased percentage of total $B$ cells in absence of a change in the absolute numbers of total B cells after aHSCT could be explained by the previously described $\mathrm{T}$ cell lymphopenia, especially $\mathrm{CD}^{+}{ }^{+} \mathrm{T}$ cell lymphopenia, following aHSCT [37].

Our six patients achieved an improved mRSS and a stabilized lung function after aHSCT, similar to other cohorts [10]. To mediate these clinical improvements,
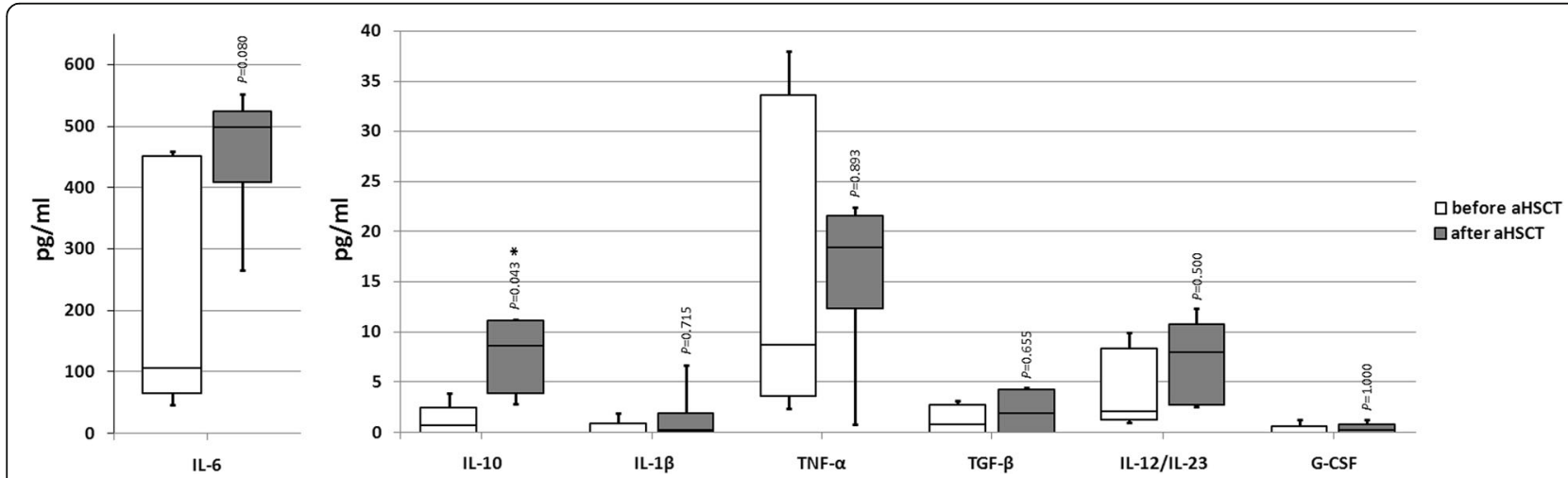

Fig. 4 Cytokine concentrations in CpG-stimulated B cell cultures (B cell purity over 95\%) from SSc patients before (white boxes; $n=5$ ) and 11-16 months after aHSCT (gray boxes; $n=6$ ). Boxes show interquartile range and median, whiskers show the lowest or highest value; ${ }^{*}<<0.05$ using the Wilcoxon signed-rank test 
the aHSCT aims to accomplish a reset of the immune system and of the B cell system [38]. A dysfunctional B cell homeostasis is postulated to play an important role in the pathogenesis of SSc [16]. aHSCT might evoke a shift of the B cell homeostasis toward a regulatory phenotype. As seen in this study, the secretion of the immune regulatory cytokine IL-10 is significantly increased after aHSCT. This could be explained by the recurrence of regulatory B cells (Bregs) after aHSCT as Bregs are often defined through their ability to produce IL-10 and are known to be an important B cell population producing IL-10 [39]. As we measured the IL-10 production in cultures of total B cells, we cannot distinguish which B cell subset mainly produced the detected IL-10. IL-10 might not only originate from Bregs. As naïve $B$ cells are described to be important producers of IL-10 [40], and we could show increased percentages and absolute numbers after aHSCT, naïve B cells might have contributed to a high extend to the IL-10 production. Therefore, the increased IL-10 concentration might be a reflection of the regenerating $B$ cell system. The production of IL-10 is not restricted to B cells, but B cell-derived IL-10 seems to be very important in the pathogenesis of SSc. This could be shown in a bleomycin-induced mouse model. Mice with a B cell-specific deficiency in the IL-10 production showed a more severe skin and lung fibrosis, compared to mice with sustained IL-10 production by B cells [41].

Administration of IL-10 to treat autoimmune diseases has been studied extensively and led to a reduction of psoriatic plaques in psoriasis and ameliorated the disease activity in intestinal bowel disease [27, 42]. In contrast to that, blocking IL-10 showed a significant clinical improvement in SLE patients in a small open-label study [43]. Therefore, using IL-10 as a therapeutic agent seems to be ambivalent due to its pleiotropic effects in different autoimmune diseases.

SSc patients can show progressive disease manifestations after aHSCT. Plasma cells can survive in bone marrow niches despite cytoreductive or immunosuppressive therapies [44], which could explain refractory disease or relapse $[45,46]$ and could be one reason why even after aHSCT further treatment is necessary. Data for treatment after aHSCT in SSc patients is limited. As an increased B cell percentage after aHSCT is present, one could speculate that the application of rituximab could be an effective therapy. In two of our patients, rituximab was used successfully without adverse effects after aHSCT due to progressive skin involvement. Application of rituximab already has shown an improvement in the mRSS and stabilized the lung function [6] or even improved the lung function [7] of SSc patients.

Limitations of our study arise due to the relatively small number of included patients. Further investigations of SSc patients after aHSCT are necessary to support our findings.

\section{Conclusion}

In summary, aHSCT causes distinct changes in the B cell compartment with an increased $\mathrm{B}$ cell percentage and a decreased memory $B$ cell compartment. The predominant B cell subpopulation after aHSCT is naïve B cells. After aHSCT, B cells show an increased secretion of the immune regulatory cytokine IL-10. All of these changes could play a role in the persisting clinical improvements of SSc patients after aHSCT. Elevated total B cell percentages and changes in cytokine concentrations offer possibilities for future treatments of progressive SSc after aHSCT.

\section{Additional file}

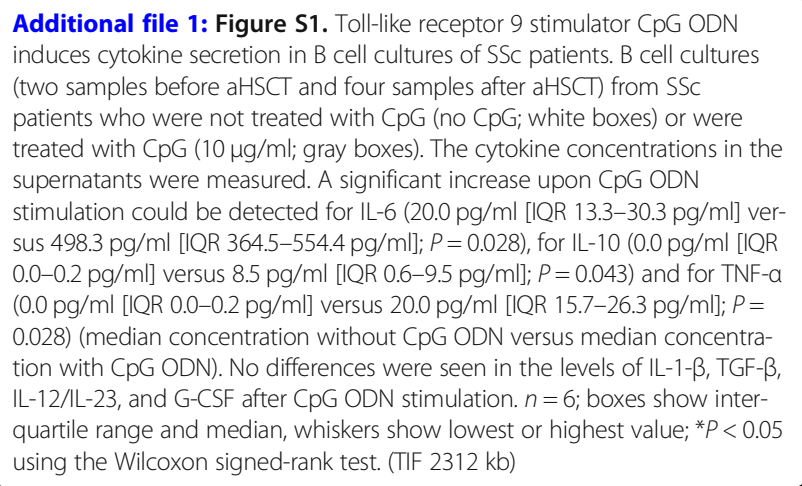

\section{Abbreviations}

ACR: American College of Rheumatology; aHSCT: Autologous hematopoietic stem cell transplantation; ATG: Anti-thymocyte globulin; BAFF: B cell activating factor; Bregs: Regulatory B cells; CD: Cluster of differentiation; CpG ODN: Cytosine guanine dinucleotide; dcSSc: Diffuse cutaneous form of systemic sclerosis; DLCO: Diffusing capacity for carbon monoxide; DMARDs: Disease-modifying anti rheumatic drugs; EULAR: The European League Against Rheumatism; FVC: Forced vital capacity; G-CSF: Granulocyte colony-stimulating factor; IgD: Immunoglobulin D; IL: Interleukin;

IQR: Interquartile range; IcSSc: Limited cutaneous form of systemic sclerosis; mRSS: Modified Rodnan skin score; PBMCs: Peripheral blood mononuclear cells; PI3K: Phosphoinositide 3-kinase; RA: Rheumatoid arthritis; SLE: Systemic lupus erythematosus; SSc: Systemic sclerosis; STAT3: Signal transducer and activator of transcription 3; TGF- $\beta$ : Transforming growth factor-beta; TNFa: Tumor necrosis factor-alpha

\section{Acknowledgements}

We thank Katharina Eckert, Silke Killinger, Brigitte Kimmel, Anette KossKinzinger, Isabelle Kuntzsch, Heide Pototzky, and Vanessa Schultz for their expert technical assistance and advice. For statistical assistance, we thank Viktoria Rücker.

\section{Funding}

This publication was funded by the German Research Foundation (DFG) and the University of Würzburg in the funding program Open Access Publishing.

\section{Availability of data and materials}

The data used and/or analyzed during the current study are available from the corresponding author on reasonable request. 


\section{Authors' contributions}

$M G, H-P T$, and MS designed the study. MG, MS, ECS, and OG were involved in the acquisition of data. MG, MS, and H-PT analyzed and interpreted the data. MG performed the statistical analysis. All authors were involved in drafting the article or revising it critically for important intellectual content, and all authors approved the final version to be submitted for publication. MG had full access to all of the data in the study and takes responsibility for the integrity of the data and the accuracy of the data analysis.

\section{Ethics approval and consent to participate}

The study was approved by the local ethics committee of the University of Würzburg. All patients gave their written informed consent.

\section{Consent for publication}

Not applicable.

\section{Competing interests}

MG received travel grants from AbbVie, Chugai, Janssen, Lilly, Pfizer, and Roche. H-PT received speaker's fees, travel grants, research funding, or compensation for consultancies or board memberships from AbbVie, Chugai/ Roche, Janssen, Lilly, Novartis, Sandoz/Hexal, Sanofi Aventis, and Shire (Baxalta). ECS received speaker's fees, travel grants, research funding, or compensation for consultancies or board memberships from AbbVie, Celgene, Chugai/Roche, Janssen-Cilag, Lilly, Novartis, and Shire (Baxalta). OG received compensation for board memberships from Novartis; speaker fees from AbbVie, Chugai, Janssen, Lilly, Novartis, and Sanofi; and travel grants from AbbVie, Chugai, Lilly, Janssen, Novartis, and MSD. MS received speaker's fees, travel grants, research funding, or compensation for consultancies or board memberships from AbbVie, Actelion, BMS, Celgene, Chugai/Roche, Genzyme, Hexal/Sandoz, Janssen-Cilag, MSD, Novartis, Pfizer, Sanofi Pasteur, Shire (Baxalta), an UCB.

\section{Publisher's Note}

Springer Nature remains neutral with regard to jurisdictional claims in published maps and institutional affiliations.

Received: 2 January 2019 Accepted: 2 April 2019

Published online: 29 April 2019

\section{References}

1. Denton CP, Khanna D. Systemic sclerosis. Lancet. 2017;390:1685-99.

2. Wollheim FA. Classification of systemic sclerosis. Visions and reality. Rheumatology (Oxford). 2005;44:1212-6.

3. Elhai M, Meune C, Avouac J, Kahan A, Allanore Y. Trends in mortality in patients with systemic sclerosis over 40 years: a systematic review and meta-analysis of cohort studies. Rheumatology (Oxford). 2012;51:1017-26.

4. Tashkin DP, Elashoff R, Clements PJ, Goldin J, Roth MD, Furst DE, et al. Scleroderma Lung Study Research Group. Cyclophosphamide versus placebo in scleroderma lung disease. N Engl J Med. 2006;354:2655-66.

5. Tashkin DP, Roth MD, Clements PJ, Furst DE, Khanna D, Kleerup EC, et al. Sclerodema Lung Study II Investigators. Mycophenolate mofetil versus oral cyclophosphamide in scleroderma-related interstitial lung disease (SLS II): a randomised controlled, double-blind, parallel group trial. Lancet Respir Med. 2016:4:708-19.

6. Jordan S, Distler JH, Maurer B, Huscher D, van Laar JM, Allanore Y, et al. EUSTAR Rituximab study group. Effects and safety of rituximab in systemic sclerosis: an analysis from the European Scleroderma Trial and Research (EUSTAR) group. Ann Rheum Dis. 2015;74:1188-94.

7. Daoussis D, Melissaropoulos K, Sakellaropoulos G, Antonopoulos I, Markatseli TE, Simopoulou T, et al. A multicenter, open-label, comparative study of Bcell depletion therapy with rituximab for systemic sclerosis-associated interstitial lung disease. Arthritis Rheum. 2017;46:625-31.

8. Khanna D, Lin CJF, Kuwana M, Allanore Y, Batalov A, Butrimiene I, Carreira P, Matucci Cerinic M, Distler O, Kaliterna DM, Mihai C, Mogensen M, Olesinska M, Pope JE, Riemekasten G, Rodriguez-Reyna TS, Santos MJ, van Laar J, Spotswood H, Siegel J, Jahreis A, Furst DE, Denton CP. Efficacy and Safety of Tocilizumab for the Treatment of Systemic Sclerosis: Results from a Phase 3 Randomized Controlled Trial [abstract]. Arthritis Rheumatol. 2018;70(suppl 10). https://acrabstracts.org/abstract/efficacy-and-safety-of-tocilizumab-forthe-treatment-of-systemic-sclerosis-results-from-a-phase-3-randomizedcontrolled-trial/. Accessed 17 Apr 2019.
9. Burt RK, Shah SJ, Dill K, Grant T, Gheorghiade M, Schroeder J, et al. Autologous non-myeloablative haemopoietic stem-cell transplantation compared with pulse cyclophosphamide once per month for systemic sclerosis (ASSIST): an open-label, randomised phase 2 trial. Lancet. 2011;378: 498-506.

10. Van Laar JM, Farge D, Sont JK, Naraghi K, Marjanovic Z, Larghero J, et al. Autologous hematopoietic stem cell transplantation vs intravenous pulse cyclophosphamide in diffuse cutaneous systemic sclerosis: a randomized clinical trial. JAMA. 2014;311:2490-8.

11. Sullivan KM, Goldmuntz EA, Keyes-Elstein L, PA MS, Pinckney A, Welch B, et al. SCOT Study Investigators. Myeloablative autologous stem-cell transplantation for severe scleroderma. N Engl J Med. 2018;378:35-47.

12. Ugor E, Simon D, Almanzar G, Pap R, Najbauer J, Németh $P$, et al. Increased proportions of functionally impaired regulatory $T$ cell subsets in systemic sclerosis. Clin Immunol. 2017;184:54-62

13. Almanzar G, Klein M, Schmalzing M, Hilligardt D, ElHajj N, Kneitz H, et al. Disease manifestation and inflammatory activity as modulators of Th17/Treg balance and RORC/FoxP3 methylation in systemic sclerosis. Int Arch Allergy Immunol. 2016;171:141-54.

14. Fuschiotti P. Current perspectives on the role of CD8+ T cells in systemic sclerosis. Immunol Lett. 2018;195:55-60.

15. Manetti M, Pratesi S, Romano E, Bellando-Randone S, Rosa I, Guiducci S, et al. Angiogenic T cell expansion correlates with severity of peripheral vascular damage in systemic sclerosis. PLoS One. 2017;12(8):e0183102.

16. Sakkas LI, Bogdanos DP. Systemic sclerosis: new evidence re-enforces the role of B cells. Autoimmun Rev. 2016;15:155-61.

17. Sato S, Hasegawa M, Fujimoto M, Tedder TF, Takehara K. Quantitative genetic variation in CD19 expression correlates with autoimmunity. J Immunol. 2000;165:6635-43.

18. Matsushita T, Hasegawa M, Yanaba K, Kodera M, Takehara K, Sato S. Elevated serum BAFF levels in patients with systemic sclerosis: enhanced BAFF signaling in systemic sclerosis B lymphocytes. Arthritis Rheum. 2006;54:192-201.

19. Volpe A, Ruzzenente O, Caramaschi P, Pieropan S, Tinazzi I, Carletto A, et al. Clinical associations of anti-CENP-B and anti-SCl70 antibody levels measured by multiplexed fluorescent microsphere immunoassay in systemic sclerosis. Rheumatol Int. 2009;29:1073-9.

20. Simon D, Balogh $P$, Bognár A, Kellermayer Z, Engelmann $P$, Németh $P$, et al. Reduced non-switched memory $B$ cell subsets cause imbalance in B cell repertoire in systemic sclerosis. Clin Exp Rheumatol. 2016;34(Suppl 100):30-6.

21. Dumoitier N, Chaigne B, Régent A, Lofek $S$, Mhibik M, Dorfmüller $P$, et al. Scleroderma peripheral B lymphocytes secrete interleukin-6 and transforming growth factor $\beta$ and activate fibroblasts. Arthritis Rheumatol. 2017;69:1078-89.

22. Wirths $S$, Lanzavecchia $A$. ABCB1 transporter discriminates human resting naive B cells from cycling transitional and memory B cells. Eur J Immunol. 2005:35:3433-41.

23. Brezinschek HP, Rainer F, Brickmann K, Graninger WB. B lymphocyte-typing for prediction of clinical response to rituximab. Arthritis Res Ther. 2012;14:R161.

24. Huang W, Sinha J, Newman J, Reddy B, Budhai L, Furie R, et al. The effect of anti-CD40 ligand antibody on B cells in human systemic lupus erythematosus. Arthritis Rheum. 2002;46:1554-62.

25. Tony HP, Roll P, Mei HE, Blümner E, Straka A, Gnuegge L, et al. FIRST/ ReFIRST study teams. Combination of B cell biomarkers as independent predictors of response in patients with rheumatoid arthritis treated with rituximab. Clin Exp Rheumatol. 2015;33:887-94.

26. Moore KW, de Waal Malefyt R, Coffman RL, O'Garra A. Interleukin-10 and the interleukin-10 receptor. Annu Rev Immunol. 2001;19:683-765.

27. Mosser DM, Zhang X. Interleukin-10: new perspectives on an old cytokine. Immunol Rev. 2008;226:205-18.

28. Candando KM, Lykken JM, Tedder TF. B10 cell regulation of health and disease. Immunol Rev. 2014:259:259-72.

29. Mavropoulos A, Simopoulou T, Varna A, Liaskos C, Katsiari CG, Bogdanos DP, et al. Breg cells are numerically decreased and functionally impaired in patients with systemic sclerosis. Arthritis Rheumatol. 2016;68:494-504.

30. Taher $\mathrm{TE}$, Ong VH, Bystrom J, Hillion $\mathrm{S}$, Simon $\mathrm{Q}$, Denton $\mathrm{CP}$, et al. Association of defective regulation of autoreactive interleukin-6-producing transitional B lymphocytes with disease in patients with systemic sclerosis. Arthritis Rheumatol. 2018;70:450-61.

31. Van den Hoogen F, Khanna D, Fransen J, Johnson SR, Baron M, Tyndall A, et al. 2013 classification criteria for systemic sclerosis: an American College of Rheumatology/European League against Rheumatism collaborative initiative. Arthritis Rheum. 2013;65:2737-47. 
32. Alexander T, Thiel A, Rosen O, Massenkeil G, Sattler A, Kohler S, et al. Depletion of autoreactive immunologic memory followed by autologous hematopoietic stem cell transplantation in patients with refractory SLE induces long-term remission through de novo generation of a juvenile and tolerant immune system. Blood. 2009;113:214-23.

33. Karnell FG, Lin D, Motley S, Duhen T, Lim N, Campbell DJ, et al. Reconstitution of immune cell populations in multiple sclerosis patients after autologous stem cell transplantation. Clin Exp Immunol. 2017;189:268-78.

34. Avanzini MA, Locatelli F, Dos Santos C, Maccario R, Lenta E, Oliveri M, et al. Lymphocyte reconstitution after hematopoietic stem cell transplantation: functional immaturity and slow recovery of memory CD27+ B cells. Exp Hematol. 2005;33:480-6.

35. Roll P, Palanichamy A, Kneitz C, Dörner T, Tony HP. Regeneration of B cell subsets after transient $B$ cell depletion using anti-CD20 antibodies in rheumatoid arthritis. Arthritis Rheum. 2006:54:2377-86.

36. Roll P, Dörner T, Tony HP. Anti-CD20 therapy in patients with rheumatoid arthritis: predictors of response and $B$ cell subset regeneration after repeated treatment. Arthritis Rheum. 2008;58:1566-75.

37. Puissant-Lubrano B, Huynh A, Attal M, Blancher A. Evolution of peripheral blood T lymphocyte subsets after allogenic or autologous hematopoietic stem cell transplantation. Immunobiology. 2014;219:611-8.

38. Alexander T, Arnold R, Hiepe F, Radbruch A. Resetting the immune system with immunoablation and autologous haematopoietic stem cell transplantation in autoimmune diseases. Clin Exp Rheumatol. 2016;34:53-7.

39. Iwata Y, Matsushita T, Horikawa M, Dilillo DJ, Yanaba K, Venturi GM, et al. Characterization of a rare IL-10-competent B-cell subset in humans that parallels mouse regulatory B10 cells. Blood. 2011;117:530-41.

40. Duddy M, Niino M, Adatia F, Hebert S, Freedman M, Atkins H, et al. Distinc effector cytokine profiles of memory and naive human B cell subsets and implication in multiple sclerosis. J Immunol. 2007;178:6092-9.

41. Matsushita T, Kobayashi T, Mizumaki K, Kano M, Sawada T, Tennichi M, et al. BAFF inhibition attenuates fibrosis in scleroderma by modulating the regulatory and effector B cell balance. Sci Adv. 2018;4:eaas9944.

42. Saxena A, Khosraviani S, Noel S, Mohan D, Donner T, Hamad AR. Interleukin10 paradox: a potent immuno regulatory cytokine that has been difficult to harness for immuno therapy. Cytokine. 2015;74:27-34.

43. Llorente L, Richaud-Patin Y, García-Padilla C, Claret E, Jakez-Ocampo J, Cardiel MH, et al. Clinical and biologic effects of anti-interleukin-10 monoclonal antibody administration in systemic lupus erythematosus. Arthritis Rheum. 2000;43:1790-800.

44. Mumtaz IM, Hoyer BF, Panne D, Moser K, Winter O, Cheng QY, et al. Bone marrow of NZB/W mice is the major site for plasma cells resistant to dexamethasone and cyclophosphamide: implications for the treatment of autoimmunity. J Autoimmun. 2012;39:180-8.

45. Radbruch A, Muehlinghaus G, Luger EO, Inamine A, Smith KG, Dörner T, et al. Competence and competition: the challenge of becoming a longlived plasma cell. Nat Rev Immunol. 2006;6:741-50.

46. Hiepe F, Dörner T, Hauser AE, Hoyer BF, Mei H, Radbruch A. Long-lived autoreactive plasma cells drive persistent autoimmune inflammation. Nat Rev Rheumatol. 2011;7:170-8.

Ready to submit your research? Choose BMC and benefit from:

- fast, convenient online submission

- thorough peer review by experienced researchers in your field

- rapid publication on acceptance

- support for research data, including large and complex data types

- gold Open Access which fosters wider collaboration and increased citations

- maximum visibility for your research: over $100 \mathrm{M}$ website views per year

At BMC, research is always in progress.

Learn more biomedcentral.com/submissions 